\title{
A new method of wound treatment: targeted therapy of skin wounds with reactive oxygen species-responsive nanoparticles containing SDF-I $\alpha$
}

This article was published in the following Dove Press journal:

International Journal of Nanomedicine

19 October 2015

Number of times this article has been viewed

\author{
Tao Tangl,* \\ Hao Jiang ${ }^{1, *}$ \\ Yuan $\mathrm{Yu}^{2, *}$ \\ Fang $\mathrm{He}^{1}$ \\ Shi-zhao Ji' \\ Ying-ying Liu' \\ Zhong-shan Wang' \\ Shi-chu Xiao' \\ Cui Tang ${ }^{3}$ \\ Guang-Yi Wang' \\ Zhao-Fan Xia' \\ 'Department of Burn Surgery, The \\ Second Military Medical University \\ Affiliated Changhai Hospital, \\ ${ }^{2}$ Department of Pharmaceutics, \\ School of Pharmacy, The Second \\ Military Medical University, ${ }^{3}$ State Key \\ Laboratory of Genetic Engineering, \\ Department of Pharmaceutical \\ Sciences, School of Life Sciences, \\ Fudan University, Shanghai, \\ People's Republic of China \\ *These authors contributed equally \\ to this work
}

Correspondence: Zhao-Fan Xia Department of Burn Surgery, The Second Military Medical University Affiliated Changhai Hospital, Shanghai 200433, People's Republic of China

Tel +86 2I 3II 6 I82I

Fax +862165589829

Email xiazhaofan_smmu@163.com

Guang-Yi Wang

Department of Burn Surgery, The Second Military Medical University Affiliated Changhai Hospital, Shanghai 200433,

People's Republic of China

Tel +86 2l 31।6 I825

Email southeast000@163.com
Objective: To accelerate wound healing through promoting vascularization by using reactive oxygen species (ROS)-responsive nanoparticles loaded with stromal cell-derived factor- $1 \alpha$ $(\mathrm{SDF}-1 \alpha)$.

Methods: The ROS-reactive nanomaterial poly-(1,4-phenyleneacetone dimethylene thioketal) was synthesized, and its physical and chemical properties were characterized. ROS-responsive nanoparticles containing SDF-1 $\alpha$ were prepared through a multiple emulsion solvent evaporation method. The loading capacity, stability, activity of the encapsulated protein, toxicity, and in vivo distribution of these nanoparticles were determined. These nanoparticles were administered by intravenous infusion to mice with full-thickness skin defects to study their effects on the directed chemotaxis of bone marrow mesenchymal stem cells, wound vascularization, and wound healing.

Results: The synthesized ROS-reactive organic polymer poly-(1,4-phenyleneacetone dimethylene thioketal) possessed a molecular weight of approximately $11.5 \mathrm{kDa}$ with a dispersity of 1.97. ROS-responsive nanoparticles containing SDF-1 $\alpha$ were prepared with an average diameter of $110 \mathrm{~nm}$ and a drug loading capacity of $1.8 \%$. The encapsulation process showed minimal effects on the activity of SDF- $1 \alpha$, and it could be effectively released from the nanoparticles in the presence of ROS. Encapsulated SDF-1 $\alpha$ could exist for a long time in blood. In mice with full-thickness skin defects, SDF-1 $\alpha$ was effectively released and targeted to the wounds, thus promoting the chemotaxis of bone marrow mesenchymal stem cells toward the wound and its periphery, inducing wound vascularization, and accelerating wound healing.

Keywords: reactive oxygen species, stromal cell-derived factor- $1 \alpha$, bone marrow mesenchymal stem cells, wound healing

\section{Introduction}

Wound healing is a complex biological process that involves multiple biological events at the cellular and molecular levels to restore the skin's barrier function, ${ }^{1}$ including the mobilization, chemotaxis, aggregation, and differentiation between bone marrow mesenchymal stem cells (BMSCs) and endothelial progenitor cells (EPCs), and the subsequent vascularization and epithelialization. ${ }^{2,3}$ Such chemotaxis and homing of BMSCs to the site of injury are mainly induced by the chemotactic function of the stromal cell-derived factor-1 (SDF-1). ${ }^{4,5}$ SDF-1 is a chemokine mutually exclusive with the CXCR4 receptor found on BMSC. Changes in SDF-1 tissue gradients are thought to be important in the mobilization and homing of BMSC from the bone marrow to the sites of injury. ${ }^{6,7}$ In this view, a high and sustained concentration of SDF-1 in the site of injury is necessary for the stem cell-based treatment of wound repair. 
Despite the considerable pharmacological activity and specificity, the direct application of SDF-1 is largely restricted by its susceptibility to enzymes, difficulty in passing through biological barriers, and rapid clearance from circulating blood, leading to limited and transitory concentration in damaged tissues after injection either topically or systemically. ${ }^{8-10}$ Therefore, ideal vector that can provide desired protection, targeted delivery to the wounds, and site-specific release is urgently needed for the SDF-1-based wound therapy. Due to the desired biodegradability, nontoxicity, and ease of modification, polymeric nanoparticles have greater potential and are been extensively used as delivery vectors for peptides or proteins to improve their stability and bioavailability. ${ }^{11-13}$ In particular, polymeric nanoparticles with the ability to change their physical and chemical properties in response to certain stimulus (eg, $\mathrm{pH}$, temperature, redox, and light) can be used to regulate the macroscopic and microscopic delivery behavior, such as targeted delivery and controlled release of the carried drug. In the case of wounds, excessive amounts of reactive oxygen species (ROS) are detected in the lesions and are considered as one of the causative factors. ${ }^{14}$ Therefore, the development of ROS-responsive polymeric delivery systems for SDF-1 that effectively dissociate and release their cargoes in the presence of high concentrations of ROS in wounded site, whereas they remain structurally stable in normal tissues with low concentrations of ROS, providing an efficient and accurate method for wound treatment. ${ }^{15,16}$

Poly-(1,4-phenyleneacetone dimethylene thioketal) (PPADT) is a new polymer that contains ROS-reactive thioketals. In the presence of ROS, thioketal bonds are cleaved, leading to the depolymerization of the polymers and the release of the cargo. However, the polymer remains stable in acidic, basic, and enzyme-rich environments. Wilson et al developed PPADT nanoparticles encapsulating siRNA targeting tumor necrosis factor- $\alpha .{ }^{16}$ After oral administration, these nanoparticles remained stable in the gastrointestinal tract, thus greatly improving the stability of orally delivered siRNA. Upon reaching the site of inflammation, the nanoparticles were phagocytosed by macrophages, in which high concentrations of ROS triggered the degradation of polymers and release the siRNA to reduce the expression of tumor necrosis factor- $\alpha$ and suppress tissue inflammation.

In this study, we used PPADT as a vehicle to package SDF-1 into nanoparticles for wound treatment. We sought to determine how the response of PPADT nanoparticles to ROS affected the release of the drug and whether nanoparticles could increase the stability of SDF-1 and form targeted site localization of macromolecular drugs (Figure 1).
The in vivo effects of these nanoparticles on BMSC chemotaxis, wound vascularization, and wound healing were also investigated.

\section{Materials and methods}

All experiments were performed in accordance with the guidelines for animal experiments of the Institutional Animal Care and Use Committee at the Changhai Hospital of the Second Military Medical University. Six-week-old male BALB/c mice weighing 20-22 $\mathrm{g}$ and 6-week-old male nude mice weighing 20-22 $\mathrm{g}$ were purchased from the Experimental Animal Center of Second Military Medical University (Shanghai, People's Republic of China). All reagents unless otherwise specified were purchased from Sigma-Aldrich (St Louis, MO, USA).

\section{Measurement of ROS levels in wounds and normal tissues}

Full-thickness skin defects were established in BALB/c mice as described earlier. ${ }^{17}$ Briefly, animals were anesthetized by intraperitoneally injected amobarbital at $40 \mathrm{mg} / \mathrm{kg}$. The back skin was shaved and disinfected with $75 \%$ ethanol, and then a piece of $8 \mathrm{~mm}$ diameter skin was removed with $8 \mathrm{~mm}$ punch biopsy together with subcutaneous tissues. The wound was covered with $3 \mathrm{M}$ surgical tape. Then, 1 days, 3 days, and 7 days later, the skin around the wound $(3 \mathrm{~mm}$ peripheral tissue around wound) and a piece of skin from a distant site were homogenized and centrifuged at $4{ }^{\circ} \mathrm{C}$, $12,000 \mathrm{rpm}$ for 20 minutes. The supernatant was taken to measure the superoxide dismutase (SOD) levels (K335-100, Biovision, USA).

\section{Synthesis of PPADT}

Synthesis of poly-(1,4-phenyleneacetone dimethylene thioketal) was determined as described in Supplementary Materials.

\section{Preparation and characterization of PPADT nanoparticles}

\section{Preparation of nanoparticles}

A multiple emulsion solvent evaporation method was used for nanoparticle preparation. ${ }^{18}$ Briefly, $1 \mathrm{mg}$ of SDF- $1 \alpha$ (CHM324 , Prospec, USA) was dissolved in $100 \mu \mathrm{L}$ of $1 \%$ sodium cholate in phosphate buffered saline (PBS) $(\mathrm{NaCl}, 137 \mathrm{mM}$; $\mathrm{KCl}, 2.7 \mathrm{mM} ; \mathrm{Na}_{2} \mathrm{PO}_{4}, 10 \mathrm{mM} ; \mathrm{KH}_{2} \mathrm{PO}_{4}, 1.76 \mathrm{mM} ; \mathrm{pH} 7.4$ ) as the internal aqueous phase, and $10 \mathrm{mg}$ of PPADT was dissolved in $1 \mathrm{~mL}$ of dichloromethane as the oil phase. They were dispersed by an intermittent ultrasound procedure in ice 


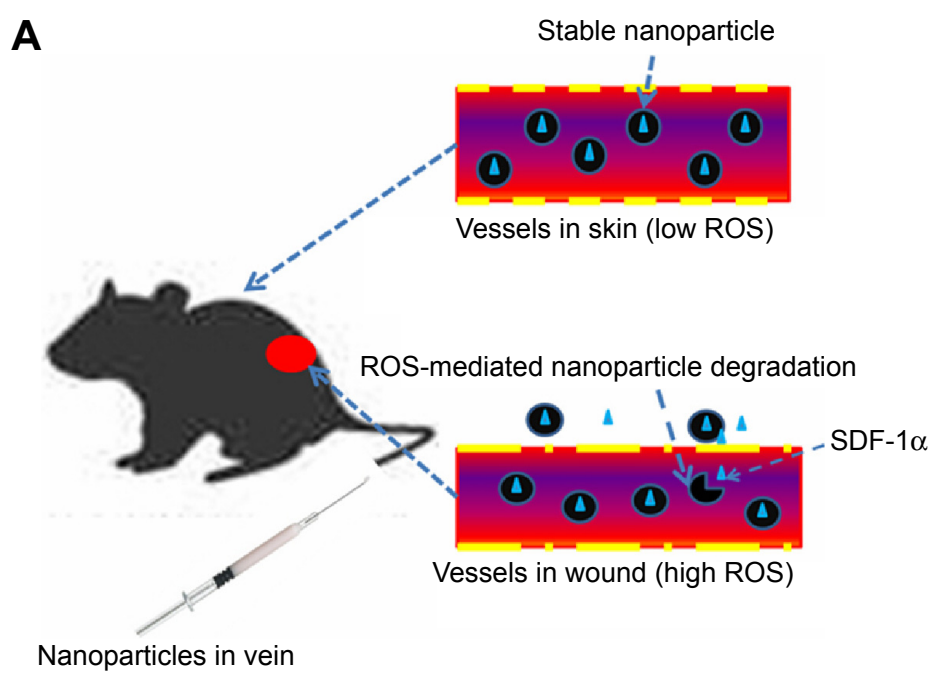

B<smiles>[Si]Cc1ccc(CS)cc1</smiles><smiles>COC(C)(C)OC</smiles>
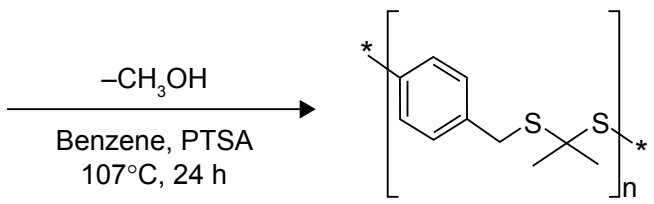

Figure I ROS sensitive nanoparticles are formulated from PPADT and release intravenous delivered chemokine at sites of wound.

Notes: (A) When delivered intravenously, SDF-I $\alpha$-PPADT nanoparticles remain stable in the normal environment of the blood vessels far away from wound protecting SDF-I $\alpha$ and preventing its release to normal tissues. However, in and around the blood vessels of wound, where tissues produce unusually high levels of ROS, the SDF-I $\alpha-$ PPADT nanoparticles degrade, thus releasing SDF-I $\alpha$ to the site of wound. (B) PPADT was synthesized using an acetal exchange reaction as previous described.

Abbreviations: ROS, reactive oxygen species; SDF-I $\alpha$, stromal cell-derived factor-I $\alpha$; h, hours; SDF-I $\alpha$-PPADT, SDF-I $\alpha$-loaded PPADT; PPADT, Poly-(I,4-phenyleneacetone dimethylene thioketal); PTSA, P-Toluene sulfonic acid.

water at $120 \mathrm{~W}, 15$ seconds $\times 2$ times, and then added into $1 \mathrm{~mL}$ of $1 \%$ sodium cholate solution (external water phase), followed by a continuous ultrasound procedure at $200 \mathrm{~W}$ for 30 seconds to form the $\mathrm{W} / \mathrm{O} / \mathrm{W}$ multiple emulsion. It was then added to $40 \mathrm{~mL}$ of $0.5 \%$ sodium cholate solution, stirred under vacuum at $4^{\circ} \mathrm{C}, 500 \mathrm{rpm}$ for 4 hours to obtain nanoparticles and remove the organic solvent. The SDF- $1 \alpha$-loaded PPADT (SDF-1 $\alpha$-PPADT) nanoparticles were collected after a centrifugation at 15,000 rpm and washed with deionized water.

Other nanoparticles were prepared in the same way, but blank nanoparticles used $1 \%$ sodium cholate solution as the internal aqueous phase, while Cy5-SDF- $1 \alpha$-PPADT nanoparticles carrying biological fluorescent dye Cy5-labeled SDF-1 $\alpha$ at the same concentration in the internal aqueous phase.

The size of the SDF- $1 \alpha$-PPADT nanoparticles was determined with a particle size analyzer (Mastersizer 2000; Malvern Instruments, Malvern, UK), and the morphology of these nanoparticles was observed with a transmission electron microscope (Tecnai G2spirit Biotwin, $120 \mathrm{kV}$ ).

\section{Drug-loading capacity of SDF-I $\alpha$-PPADT nanoparticles}

Nanoparticles prepared as above were vacuum dried at $-40^{\circ} \mathrm{C}$, weighed, dissolved in $1 \mathrm{~mL}$ dichloromethane, and then centrifuged at $12,000 \mathrm{rpm}$ for 10 minutes to remove the supernatant. Appropriate amount of PBS was added to dissolve the precipitated SDF- $1 \alpha$, and its concentration was analyzed using enzyme-linked immunosorbent assay (ELISA) (KA2692, ABNOVA). This content was compared with the weight of the nanoparticles to calculate the drugloading capacity.

\section{In vitro release of SDF-I $\alpha$ from SDF-I $\alpha$-PPADT nanoparticles}

PBS and the Fenton's reagent were used as media to determine the release of SDF- $1 \alpha$ from the nanoparticles in response to ROS. The Fenton's reagent is a strong oxidizing agent, which contains hydroxyl radicals resulting from the catalyzation of $\mathrm{H}_{2} \mathrm{O}_{2}$ by $\mathrm{Fe}^{2+}$ and is used to simulate an in vivo environment with high levels of ROS. Drug release experiments were performed as described earlier. ${ }^{19}$ Briefly, $1 \mathrm{mg}$ of nanoparticles was added to $1 \mathrm{~mL}$ of release medium and stirred at $4^{\circ} \mathrm{C}, 100 \mathrm{rpm}$. After 30 minutes, 1 hour, 3 hours, 6 hours, 12 hours, 24 hours, and 48 hours, $1 \mu \mathrm{L}$ of sample was removed and replenished with the equal volume of the release medium. ELISA (KA2692, ABNOVA) was used to determine the SDF- $1 \alpha$ concentrations in the samples taken above, and the rates of drug release were calculated. 
Analysis of the activity of SDF-I $\alpha$ in the SDF-I $\alpha$ PPADT nanoparticles

SDF-1 $\alpha$ was extracted from the nanoparticles as described earlier. Briefly, in the transwell system (Corning Incorporated, Corning, NY, USA), a low glucose Dulbecco's Modified Eagle's Medium (DMEM) was added in the lower chambers and supplemented with $0 \mathrm{ng} / \mathrm{mL}, 1 \mathrm{ng} /$ $\mathrm{mL}, 10 \mathrm{ng} / \mathrm{mL}, 100 \mathrm{ng} / \mathrm{mL}$, and extracted SDF-1 $\alpha$ or 100 ng/mL SDF-1 $\alpha$ standard. BMSCs (MUBMX-01001; Cyagen, People's Republic of China) were plated into the upper chambers at $5 \times 10^{4}$ cells $/$ well in low-glucose DMEM and cultured for 6 hours. Adherent BMSCs in the upper chambers were removed, and cells in the lower chambers were stained with methyl violet to count the number of migrated BMSCs.

\section{Toxicity analysis of the SDF-I $\alpha$-PPADT nanoparticles}

\section{In vitro cytotoxicity analysis}

BMSCs were cultured in 6-well plates in a low-glucose DMEM medium supplemented with $10 \%$ fetal bovine serum (Thermo Fisher Scientific, Waltham, MA, USA). Cells were plated at a density of $1 \times 10^{5}$ cells/well and cultured for 24 hours before adding PBS or SDF-1 $\alpha$-PPADT nanoparticles at $1 \mathrm{mg} / \mathrm{mL}, 10 \mathrm{mg} / \mathrm{mL}$, or $100 \mathrm{mg} / \mathrm{mL}$. The cells were further cultured for 24 hours. A WST-1 Cell Proliferation and Cytotoxicity Assay Kit (C0035; Beyotime, People's Republic of China) was used to determine the cell proliferation rate.

\section{In vivo toxicity analysis}

Eighty BALB/c mice were randomly divided into four groups and were injected with $0.1 \mathrm{~mL}$ of saline or $1 \mathrm{mg} / \mathrm{kg}, 10 \mathrm{mg} / \mathrm{kg}$, or $100 \mathrm{mg} / \mathrm{kg}$ of SDF-1 $\alpha$-PPADT nanoparticles resuspended in saline through the tail vein. Mice were monitored for 1 week for survival, after which the animals were killed, and the level of creatine kinase, aspartate aminotransferase, and alanine aminotransferase in the serum was measured using an automated biochemical analyzer. Major organs including the heart, liver, spleen, lung, kidney, and testicle were fixed in $10 \%$ formalin and embedded in paraffin. Tissue sections were stained with hematoxylin and eosin for morphological analysis.

\section{Wound targeting of SDF- I $\alpha$-PPADT nanoparticles}

Nine nude mice were randomly divided into three groups, and a full-thickness skin defect measuring $8 \mathrm{~mm}$ in diameter was created on the back of each mouse. After 12 hours, mice were injected with $0.1 \mathrm{~mL}$ of saline or $10 \mathrm{mg}$ of blank PPADT or Cy5-SDF-1 $\alpha$-PPADT nanoparticles. After another 12 hours, an in vivo imager (IVIS LaminqII, Caliper LifeSciences, Hopkinton, MA, USA) was used to observe the distribution of fluorescence in these animals. The exposure time was 60 seconds.

\section{BMSC chemotaxis, wound revascularization, and wound healing \\ Wound healing}

Thirty BALB/c mice with full-thickness skin defects of $8 \mathrm{~mm}$ in diameter were divided into five groups of six mice per group. These mice received daily injections of 1) $0.1 \mathrm{~mL}$ of saline, 2) $1 \mathrm{mg} / \mathrm{kg}$ of blank PPADT nanoparticles, 3) $5 \mu \mathrm{g} / \mathrm{kg}$ of SDF-1 $\alpha$, 4) $1 \mathrm{mg} / \mathrm{kg}$ of blank PPADT nanoparticles and $18 \mu \mathrm{g} / \mathrm{kg}$ of SDF- $1 \alpha$, or 5) $1 \mathrm{mg} / \mathrm{kg}$ of SDF- $1 \alpha-P P A D T$ nanoparticles through the tail vein. Wound closing was observed on days $1,3,5,7$, and 10, and mice were killed on day 10. Skin around the wounds (3 $\mathrm{mm}$ peripheral tissue around wound) were fixed in $10 \%$ formalin and embedded in paraffin, and the sections were immunohistochemically stained for CD31. Vascularization of the wounds was determined by the number of CD31-positive cells.

\section{BMSCs chemotaxis and homing}

Green fluorescent protein (GFP)-labeled BMSCs (GFPBMSCs) was purchased from MUBMX-01101, Cyagen, People's Republic of China. Thirty BALB/c mice with full-thickness skin defects measuring $8 \mathrm{~mm}$ in diameter were divided into five groups of six mice per group. These mice received daily injections of 1) $5 \times 10^{5}$ of GFP-BMSCs, 2) $5 \times 10^{5}$ of GFP-BMSCs $+0.5 \mathrm{mg} / \mathrm{kg}$ of blank PPADT nanoparticles, 3) $5 \times 10^{5}$ of GFP-BMSCs $+5 \mu \mathrm{g} / \mathrm{kg}$ of SDF- $1 \alpha$, 4) $5 \times 10^{5}$ of GFP-BMSCs $+0.5 \mathrm{mg} / \mathrm{kg}$ of blank PPADT nanoparticles $+5 \mu \mathrm{g} / \mathrm{kg}$ of SDF- $1 \alpha$, or 5 ) $5 \times 10^{5}$ of GFP-BMSCs $+0.5 \mathrm{mg} / \mathrm{kg}$ of SDF- $1 \alpha$-PPADT nanoparticles through the tail vein. After 3 days, skin tissues around the wounds were collected. Frozen sections were stained for CD31 with immunofluorescence to identify CD31-positive cells derived from GFP-BMSCs.

\section{Data analysis}

All data analysis was performed with the SPSS17.0 statistical analysis software. Overall comparisons of grouped data were analyzed with a one-way analysis of variance. In addition, the unpaired Student's $t$-test was used to compare individual groups. Values are expressed as mean \pm scanning electron microscopy. Statistical significance was defined by $P<0.05$. 


\section{Results}

\section{ROS levels were higher in the wounds}

SOD is one of the main enzymes in the body that removes ROS. SOD is consumed during its reaction with ROS, so its activity is negatively related to the level of ROS and can gradually return to normal level after the ROS are removed. SOD activity in the wounds was $0.715 \pm 0.093 \mathrm{U} / \mathrm{mg}$ protein on day $1,0.631 \pm 0.116 \mathrm{U} / \mathrm{mg}$ protein on day 3 , and $0.825 \pm 0.076 \mathrm{U} /$ mg protein on day 7 (Figure 2 ). Normal skin showed slightly higher SOD activity of $3.031 \pm 0.283 \mathrm{U} / \mathrm{mg}$ protein on day 7 , suggesting that the wounds and the surrounding tissues contained high levels of ROS.

\section{Characterization of PPADT polymers}

The characterization of PPADT polymers was determined as described in Supplementary Materials.

\section{Characterization of the prepared nanoparticles}

\section{Particle size and morphology}

The diameters of the Cy5-SDF- $1 \alpha-P P A D T$, SDF- $1 \alpha-P P A D T$, and blank nanoparticles tested by dynamic light scattering were $124.7 \pm 27.5 \mathrm{~nm}, 113.8 \pm 40.9 \mathrm{~nm}$, and $113.4 \pm 40.7 \mathrm{~nm}$, respectively. During its observation with transmission electron microscope, the nanoparticles appeared uniform in

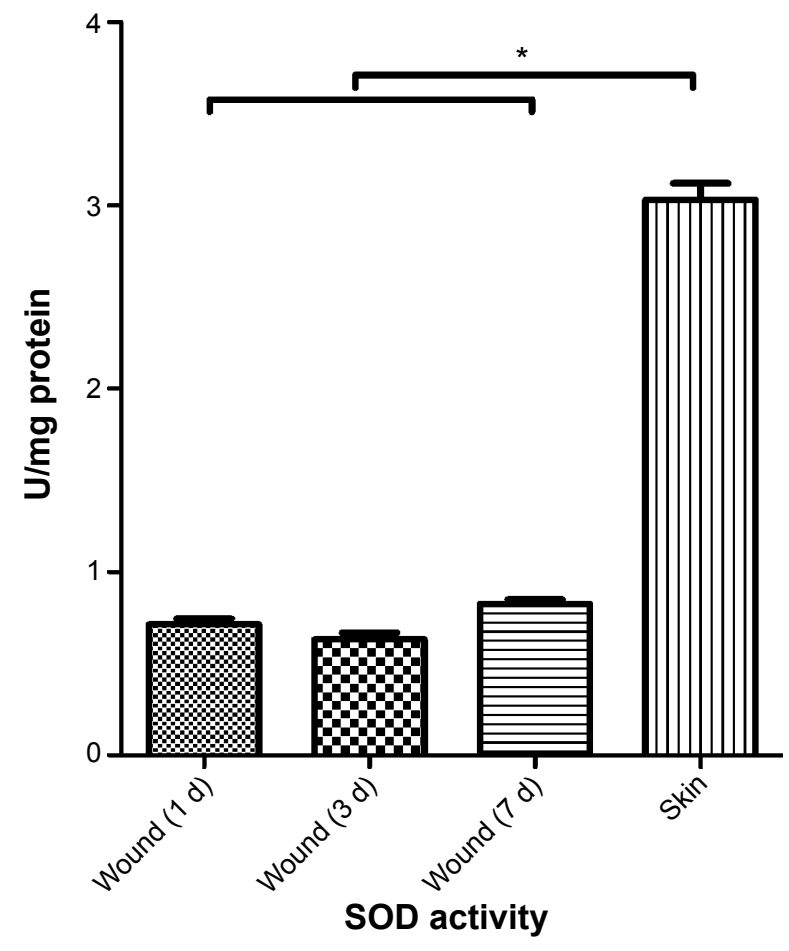

Figure 2 Activity of superoxide dismutase (SOD) in skin wounds. Note: $\mathrm{n}=6, * \mathrm{p}<0.000 \mathrm{I}$.

Abbreviations: SOD, superoxide dismutase; d, day. size with no adhesion (Figure 3 ). The drug-loading capacity of the nanoparticles was $1.8 \%$.

In vitro release of the carried drug from SDF-I $\alpha$ PPADT nanoparticles

When put into PBS or the Fenton's reagent, the nanoparticles showed a significant burst release within 1 hour in both the buffers (Figure 4). In PBS, the nanoparticles released 23\% of the loaded drug following 48-hour incubation. Remarkable accelerated release was observed in the Fenton's reagent. By 8 hours, $60 \%$ of the drug had been released. By 48 hours, the drug release was nearly complete. Such result indicated that the SDF-1 $\alpha$-PPADT nanoparticles were relatively stable in a normal environment without ROS, but the presence of ROS triggered a rapid release of the carried drug within 48 hours.

\section{In vivo release of SDF-I $\alpha$}

After intravenous injection of SDF- $1 \alpha$, the serum SDF- $1 \alpha$ level increased highly and then dropped rapidly to normal levels within 2 hours. When unwounded mice were given SDF$1 \alpha$-PPADT nanoparticles, SDF-1 $\alpha$ was slowly released to yield the blood level of $\sim 400 \mathrm{pg} / \mathrm{mL}$ at 24 -hour postinjection, which was higher than that in saline-injected mice. However, in mice with full-thickness skin defects, the SDF-1 $\alpha$ level increased significantly and remained stable for 24 hours, after which it gradually returned to normal levels (Figure 5A). Mice with full-thickness skin defects and sham-operated mice were injected with saline or SDF1 $\alpha$-PPADT nanoparticles, and the level of SDF1 $\alpha$ in the skin was measured. Wounded mice receiving SDF1 $\alpha$-PPADT nanoparticles exhibited high levels of SDF1 $\alpha$ in the wounds (Figure 5B).

\section{Activity of SDF- I $\alpha$ encapsulated in nanoparticles}

To determine whether the process of nanoparticle preparation affected the biological activity of SDF-1 $\alpha$, we used a transwell system to determine the chemotactic activity of SDF-1 $\alpha$ released from the nanoparticles and compared it with that of the SDF- $1 \alpha$ standard. As shown in Figure 6, when the lower chamber of the transwell system contained only low-glucose DMEM medium, nearly no BMSCs migrated from the upper chambers into the lower chambers after 6-hour incubation. When the medium in the lower chambers was supplemented with $100 \mathrm{ng} / \mathrm{mL}$ of SDF-1 standard or $100 \mathrm{ng} / \mathrm{mL}$ of SDF- $1 \alpha$ extracted from the nanoparticles, many BMSCs migrated to the lower chambers. The number of migrated cells from these two conditions showed a ratio of 1:0.73 (Figure 6), indicating that SDF-1 $\alpha$ 

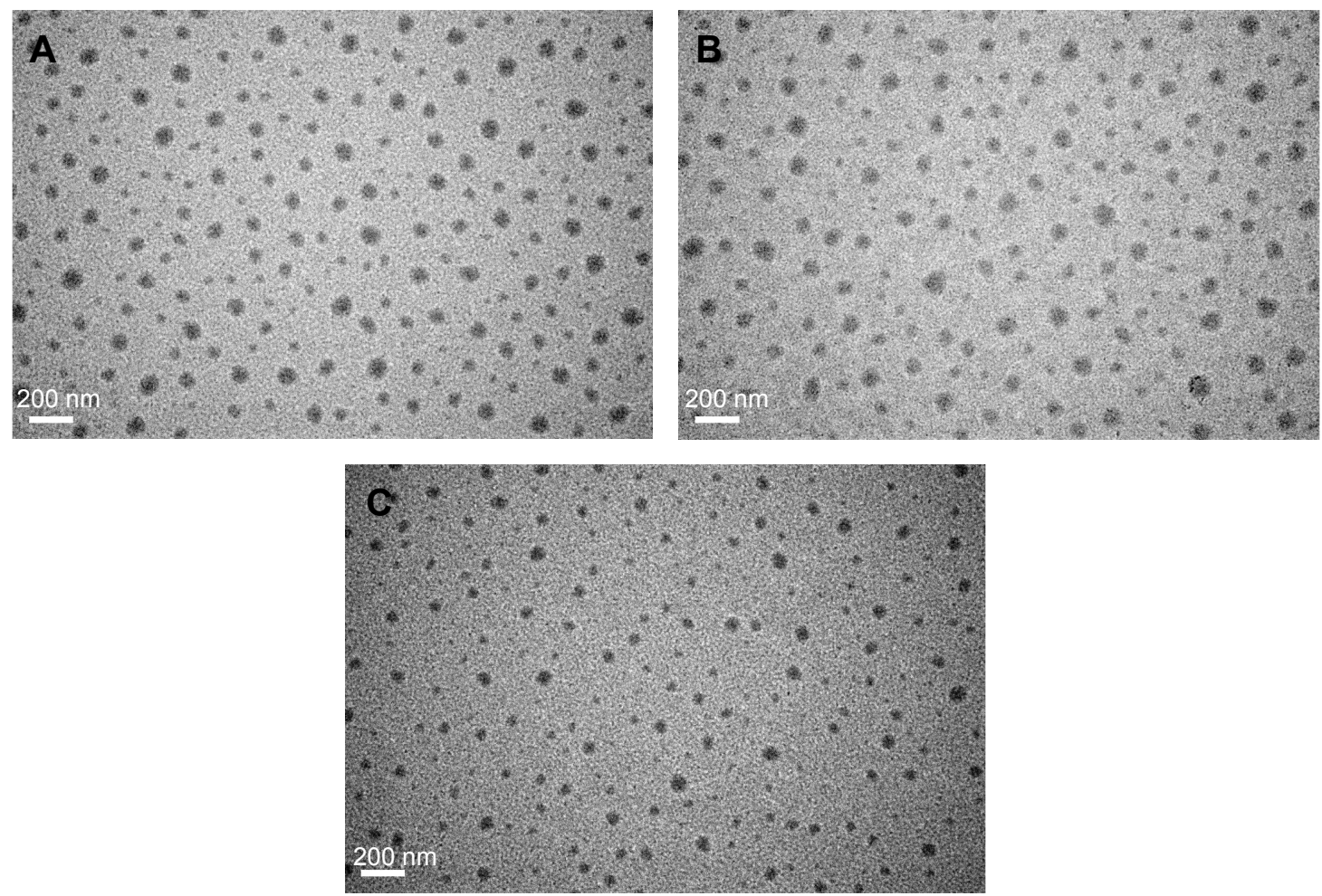

Figure 3 Morphology of SDF-I $\alpha$-PPADT nanoparticles.

Notes: Nanoparticles was observed by a transmission electron microscope. (A) SDFI $\alpha$-PPADT nanoparticles, (B) Cy5-SDFI $\alpha$-PPADT nanoparticles, and (C) PPADT nanoparticles.

Abbreviations: SDF-I $\alpha$-PPADT, SDF- I $\alpha$-loaded PPADT; SDF- $\alpha$, stromal cell-derived factor-I $\alpha$; PPADT, poly-(I,4-phenyleneacetone dimethylene thioketal).

released from the nanoparticles retained the majority of chemotactic activity.

\section{SDF- $\mid \alpha-P P A D T$ nanoparticle toxicity test In vitro cytotoxicity}

To determine whether the SDF-1 $\alpha$-PPADT nanoparticles were cytotoxic, a CCK8 assay was performed to determine

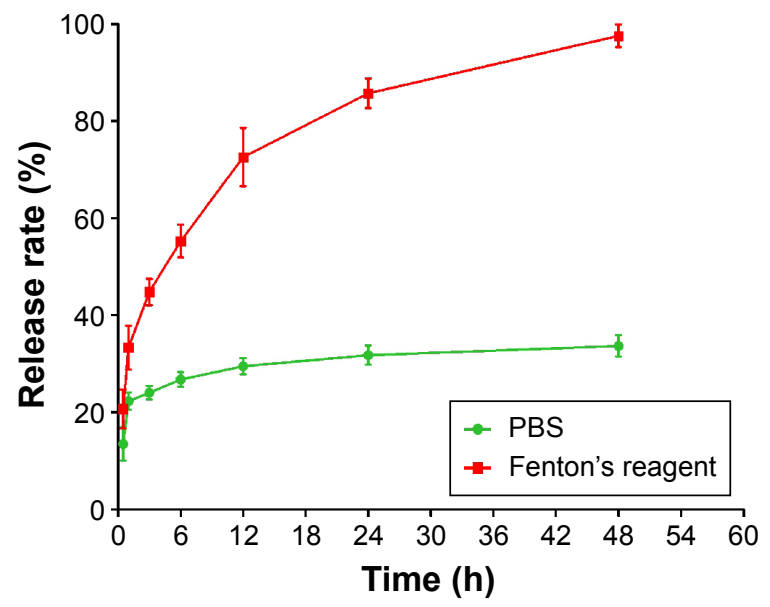

Figure 4 In vitro release of SDF-I $\alpha$ from nanoparticles in PBS and Fenton's agent. Note: $n=3$.

Abbreviations: PBS, phosphate buffered saline; SDF-I $\alpha$, stromal cell-derived factor-I $\alpha$; h, hours. the effect of various concentrations of SDF-1 $\alpha$-PPADT nanoparticles on BMSCs proliferation. When BMSCs were cultured in the presence of different concentrations of SDF$1 \alpha$-PPADT nanoparticles for 24 hours, the cell proliferation rate was not significantly different from that of the control cells $(P>0.05)$ (Figure 7A), suggesting that SDF-1 $\alpha$-PPADT nanoparticles had little effect on cell proliferation and minimal cytotoxicity.

\section{In vivo toxicity}

To determine the biological toxicity of SDF-1 $\alpha$-PPADT nanoparticles, various concentrations of SDF- $1 \alpha$-PPADT nanoparticles were injected into mice through the tail vein, and the survival of these mice was monitored for 1 week. Liver and kidney functions and the morphology of major organs were analyzed after 1 week. All mice injected with the nanoparticles survived. Creatine kinase, aminotransferase, and alanine aminotransferase were not significantly changed $(P>0.05)$ (Figure 7B). Histological examination of the major organs and tissues showed no morphological abnormalities or infiltration of inflammatory cells, indicating that the nanoparticles had a good biological compatibility (Figure 8). 
A

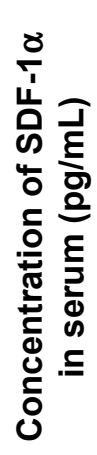

B

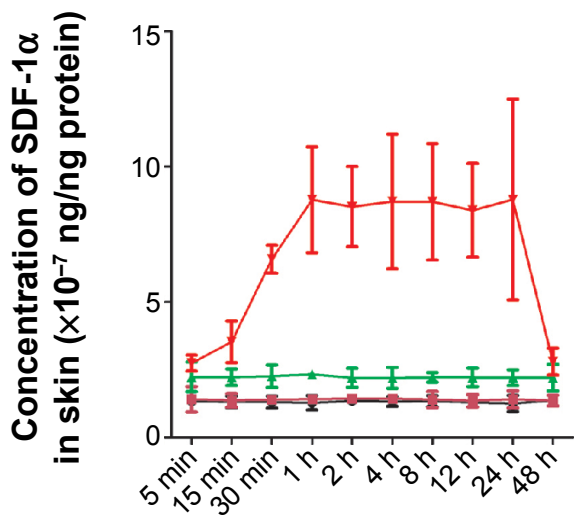

Time

Time

\begin{tabular}{|ll|}
- Sham + saline & - Sham $+1 \mathrm{mg} / \mathrm{kg}$ SDF-1 $\alpha$-PPADT NP \\
- Wound + saline & - Wound $+0.5 \mathrm{mg} / \mathrm{kg}$ SDF-1 $\alpha$-PPADT NP \\
- Wound $+1 \mathrm{mg} / \mathrm{kg} \mathrm{SDF-1} \alpha$-PPADT NP & $\rightarrow$ Wound $+5 \mathrm{mg} / \mathrm{kg}$ SDF-1 $\alpha$-PPADT NP \\
$\rightarrow$ Sham $+90 \mu \mathrm{g} / \mathrm{kg}$ SDF-1 $\alpha$ & \\
\hline
\end{tabular}

Figure 5 In vivo release of SDF-I $\alpha$ from nanoparticles.

Notes: Mice with full-thickness skin defects and sham-operated mice were injected with saline, SDF-I $\alpha$, or SDFI $\alpha$-PPADT nanoparticles and then the levels of SDF-I $\alpha$ in circulatory system $(\mathbf{A})$ and skin (B) were measured.

Abbreviations: SDF-I $\alpha$-PPADT, SDF-I $\alpha$-loaded PPADT; SDF-I $\alpha$, stromal cell-derived factor-I $\alpha$; PPADT, poly-(I,4-phenyleneacetone dimethylene thioketal); min, minutes; $h$, hours; Sham, no treatment was taken in this group; NP, nanoparticle.
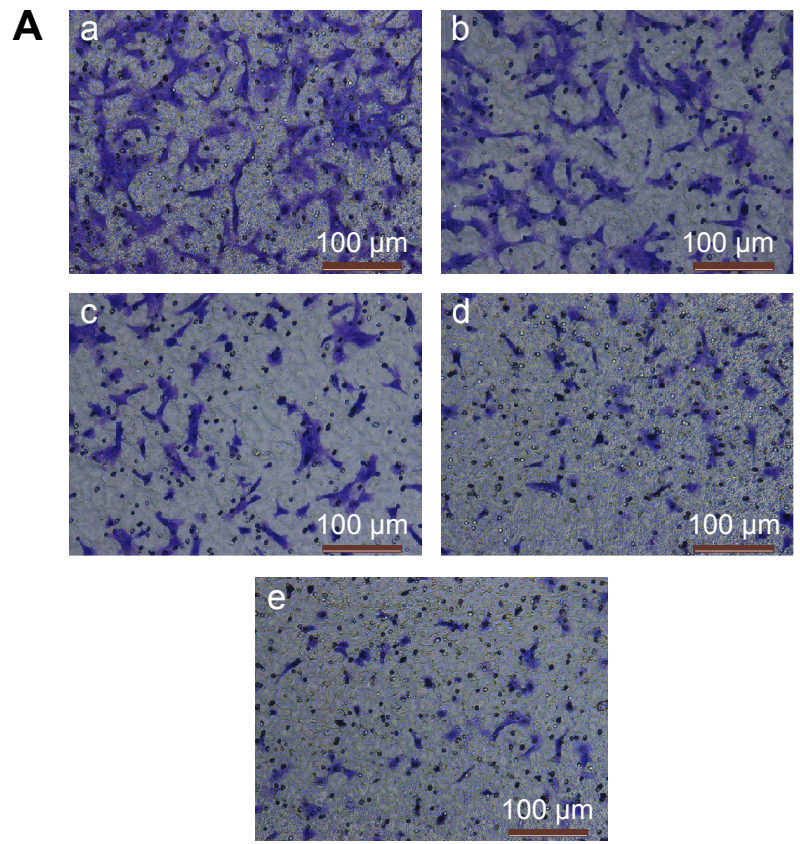

B

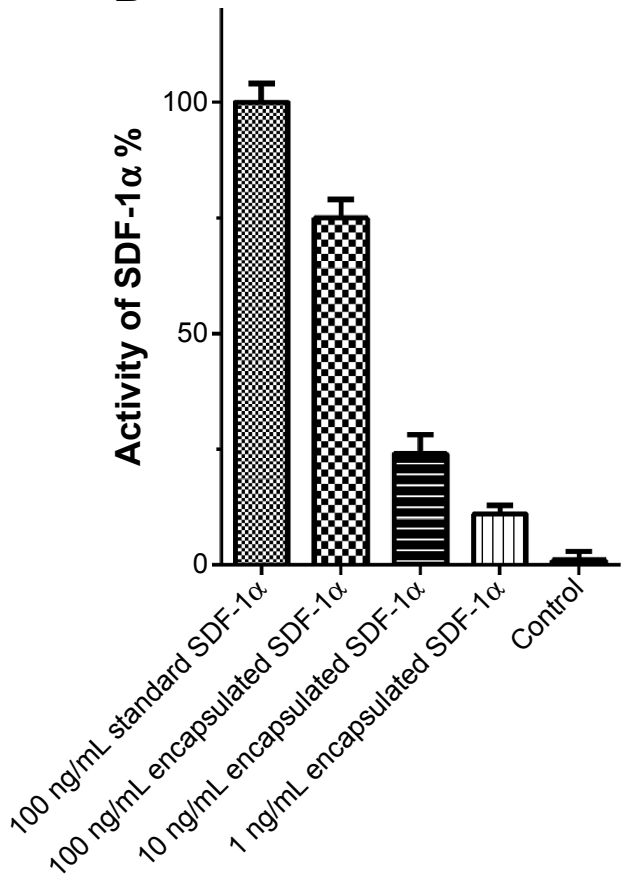

\section{Group}

Figure 6 Results of Transwell chamber test.

Notes: (A) After co-cultured in Transwell system for 12 hours, most of the BMSCs that were co-cultured with $100 \mathrm{ng} / \mathrm{mL}$ standard SDF-I $\alpha$ were migrated to the lower chamber (a), the number of BMSCs that migrated to lower chamber co-cultured with $100 \mathrm{ng} / \mathrm{mL}$ encapsulated SDF-I $\alpha$ (b) was a little less than the former, the number of BMSCs that migrated to lower chamber co-cultured with $10 \mathrm{ng} / \mathrm{mL}$ encapsulated SDF-I $\alpha$ (c), I ng/mL encapsulated SDF-I $\alpha$ (d) and PBS (e) reduced progressively. (B) The chemotactic activity of SDF-I $\alpha$ was showed by the ratio of migrated BMSCs as follows: $100.0 \pm 2.9(100 \mathrm{ng} / \mathrm{mL}$ standard SDF- $1 \alpha): 73.9 \pm 2.9(100 \mathrm{ng} / \mathrm{mL}$ encapsulated SDF- $\alpha$ ): $30.8 \pm 5.8(I 0 \mathrm{ng} / \mathrm{mL}$ encapsulated SDF- $\mid \alpha): 10.1 \pm 2.3(I \mathrm{ng} / \mathrm{mL}$ encapsulated SDF- $\mid \alpha): 0.0 \pm I .2($ control $)(\mathrm{n}=\mid 0)(P<0.0001)$.

Abbreviations: SDF-I $\alpha$, stromal cell-derived factor-I $\alpha$; BMSCs, bone marrow mesenchymal stem cells. 
A

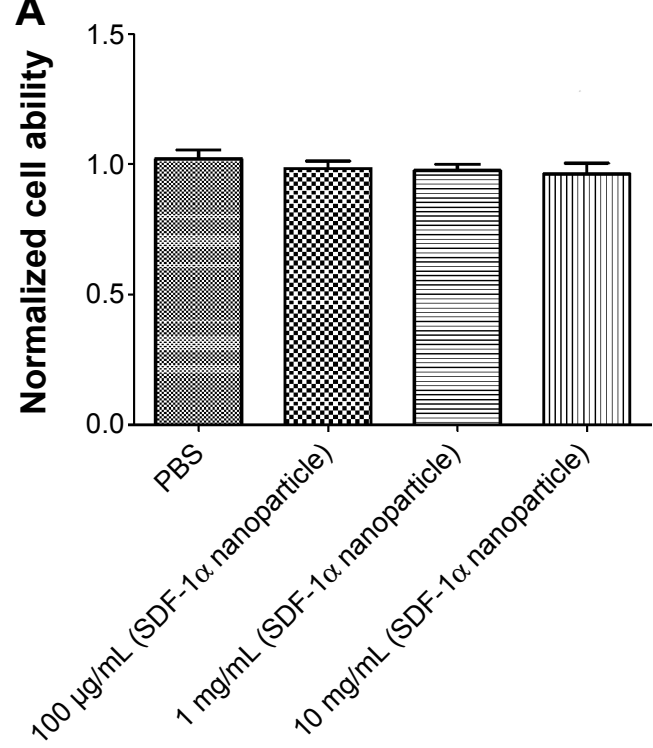

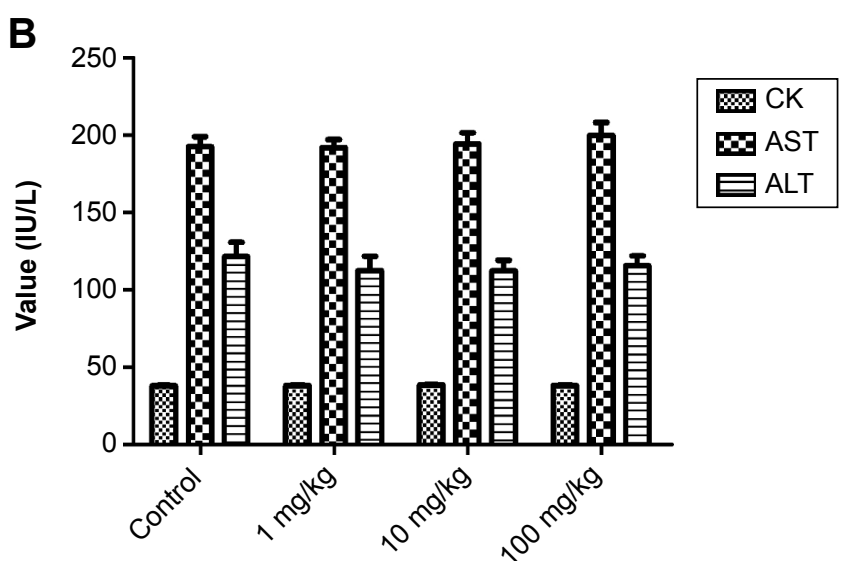

Values of injury makers of mice administrated with different dose of SDF-1 $\alpha$-PPADT nanoparticle in vein

Figure 7 Toxicity analysis of nanoparticles.

Notes: (A) After cultured with PBS and $100 \mu \mathrm{g} / \mathrm{mL}, 1 \mathrm{mg} / \mathrm{mL}, 10 \mathrm{mg} / \mathrm{mL}$ SDF-I $\alpha$-PPADT nanoparticles for 24 hours, the cell proliferation rates of BMSCs almost identical ( $P=0.638$ ). (B) 7 days after injected intravenously with saline (control), I mg/kg, $10 \mathrm{mg} / \mathrm{kg}$ and $100 \mathrm{mg} / \mathrm{kg}$. SDF-I $\alpha$-PPADT nanoparticles, the injury markers CK ( $P=0.679)$, AST $(P=0.853)$ and ALT $(P=0.83 \mathrm{I})$ showed no significantly differences.

Abbreviations: CK, creatine kinase; AST, aspartate aminotransferase; ALT, alanine aminotransferase; PBS, phosphate buffered saline; PPADT, poly-(I,4-phenyleneacetone dimethylene thioketal); SDF-I $\alpha$-PPADT, SDF-I $\alpha$-loaded PPADT; SDF-I $\alpha$, stromal cell-derived factor-I $\alpha$.

\section{Wound-targeted release of SDF- $\mid \alpha-$ PPADT nanoparticles}

The wounds and the surrounding tissues became fluorescent 12 hours after tail vein injection of Cy5-SDF-1 $\alpha$-PPADT nanoparticles into mice with full-thickness skin defects, while the other parts of the bodies were not fluorescent, suggesting that the PPADT nanoparticles responded to the high levels of ROS in the wounds, resulting in wound-targeted drug delivery (Figure 9).

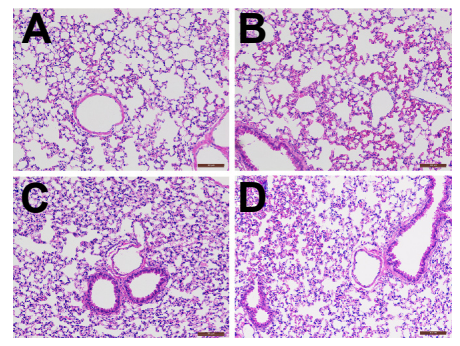

Lung

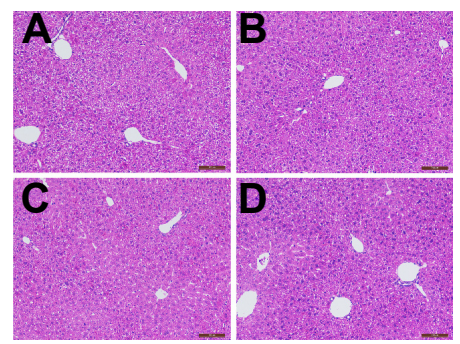

Liver

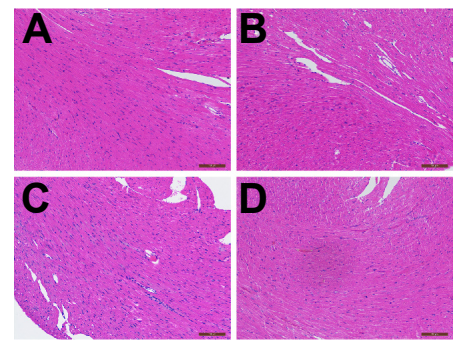

Heart

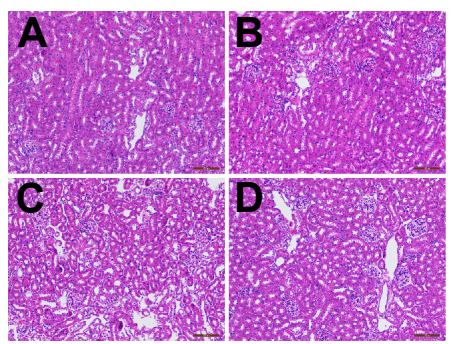

Kidney

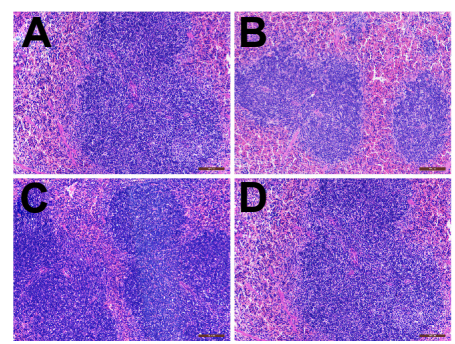

Spleen

Figure 8 HE staining of major organs $(n=8)$.

Notes: BALB/c mice were randomly divided into four groups and were injected with $0.1 \mathrm{~mL}$ of saline (A), or I mg/kg (B), $10 \mathrm{mg} / \mathrm{kg}$ (C), or $100 \mathrm{mg} / \mathrm{kg}$ (D) of SDF-I $\alpha$-PPADT nanoparticles resuspended in saline through the tail vein. Histological examination of the major organs and tissues showed no morphological abnormalities or infiltration of inflammatory cells.

Abbreviations: SDF-I $\alpha$-PPADT, SDF-I $\alpha$-loaded PPADT; SDF- $\alpha$, stromal cell-derived factor-I $\alpha$; PPADT, poly-(I,4-phenyleneacetone dimethylene thioketal); HE staining, hematoxylin-eosin staining. 


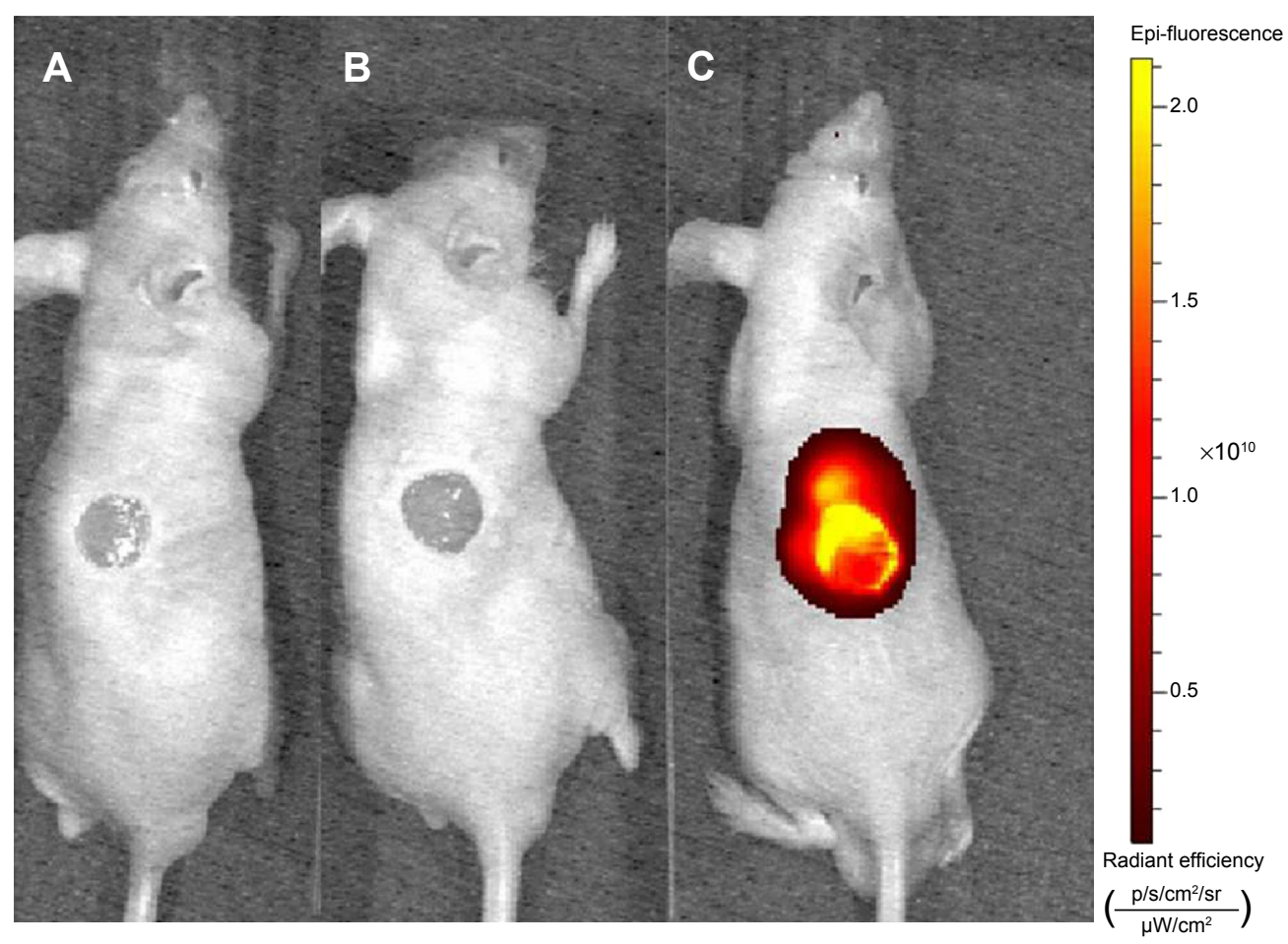

Figure 9 Wound-targeted release of nanoparticles.

Notes: Nude mice with full-thickness skin defects were injected with (A) saline, (B) blank nanoparticles, or (C) Cy5-SDF-I $\alpha$-PPADT nanoparticles via the tail vein and detected for Cy 5 fluorescence 12 hours later.

\section{SDF- $\mid \alpha-P P A D T$ nanoparticles promoted BMSC chemotaxis, wound revascularization, and wound healing}

To determine the effects of SDF-1 $\alpha$-PPADT nanoparticles on wound healing, these particles were injected intravenously into mice with full-thickness skin defects. Mice injected with SDF- $1 \alpha-P P A D T$ nanoparticles displayed significantly accelerated wound healing. The wounds on these mice were more vascularized and closed sooner than those on mice that received blank nanoparticles, pure SDF-1 $\alpha$, or blank nanoparticles combined with pure SDF-1 $\alpha$ (Figure 10).

To determine whether the accelerated wound healing was due to SDF-1 $\alpha$ 's function in promoting homing of BMSCs or EPCs to the wounds, thereby inducing wound vascularization, exogenous BMSCs labeled with GFP were infused into wounded mice. Three days later, mice in the SDF- $1 \alpha$-PPADT group had significantly more $\mathrm{GFP}^{+} / \mathrm{CD} 31^{+}$cells accumulated in their wounds than those in the blank nanoparticles, pure SDF-1 $\alpha$, or blank nanoparticles combined with pure SDF-1 $\alpha$ groups, suggesting that SDF- $1 \alpha-P P A D T$ nanoparticles promoted BMSC homing to the wounds (Figure 11).

\section{Discussion}

Angiogenesis is one of the key processes in the repair of deep wounds. Angiogenic stem cells play a critical role in this process, and the efficiency of their homing to the wounds directly affects wound healing. Various types of stem cells, including EPCs and their precursors, BMSCs, have been used in wound treatment to accelerate wound angiogenesis and promote wound repair. ${ }^{20,21}$ The homing of EPCs is dependent on SDF-1 $\alpha$-mediated chemotaxis. Systemic and topical administration of SDF- $1 \alpha$ is faced with the common limitations of protein and peptide drugs, namely a short half-life in vivo, fast clearance from the body, and low bioavailability, ${ }^{22,23}$ especially difficulties in the formation of a concentration gradient necessary to induce chemotaxis of stem cells in the local wound area.

Biodegradable polymers can be used as vehicles to carry protein and peptide drugs, and this method can improve the stability and bioavailability of macromolecular drugs effectively. By adjusting the physical and chemical characteristics of the polymers, drugs can be targeted to various lesions and tissues, where they are slowly released over a prolonged period of time. ${ }^{24}$ To achieve the targeted characteristic, the key is to determine the specific biological properties of local tissue. Local wound has various biological characteristics different from normal tissue, for example, peroxidation. Excessive amount of ROS commonly seen in the sites of trauma, infection, and ischemia is an inevitable pathological phenomenon, which can trigger 

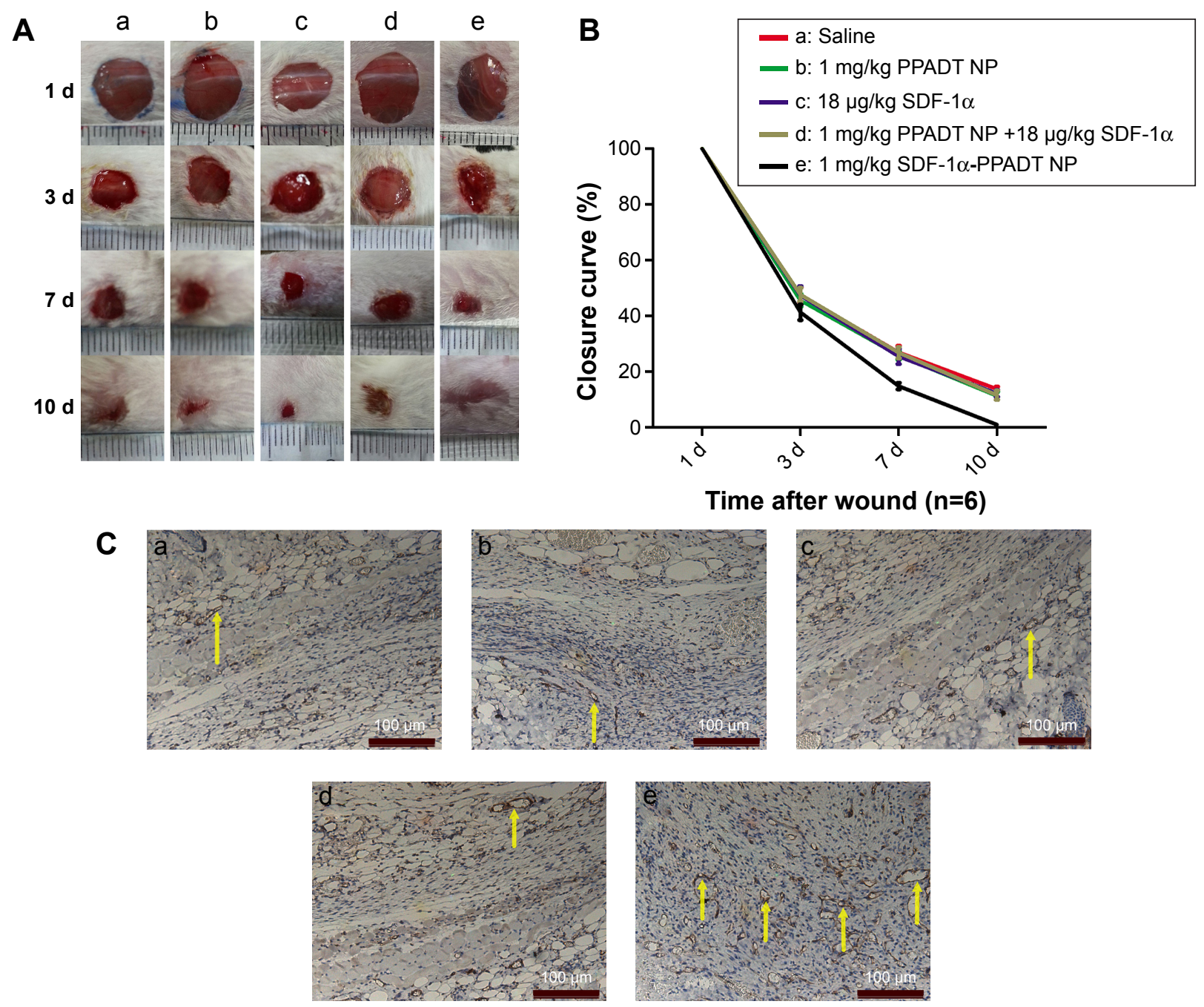

Figure 10 SDF-I $\alpha$-PPADT nanoparticles that promoted wound vascularization and wound healing.

Notes: (A) 6-week-old BALB/c mice with full-thickness skin defects were injected intravenously with (a) saline, (b) blank nanoparticles, (c) blank nanoparticles + SDF-I $\alpha$, (d) SDFI $\alpha$, (e) SDF-I $\alpha$-PPADT nanoparticles. The mice that received SDF-I $\alpha$-PPADT nanoparticles displayed the most accelerated wound healing. Wounds were fully closed on day I0, and the wounds on mice in the other four groups were still not completely closed. (B) The closure curve showed higher wound closure rate in mice injected with SDFI $\alpha$-PPADT nanoparticles $(P<0.05)$. (C) Immunohistochemistry assays showed that the wounds on mice injected intravenously with SDFI $\alpha$-PPADT nanoparticles (e) contained more CD3I-positive blood vessels than those on mice injected intravenously with (a) saline, (b) blank nanoparticles, (c) blank nanoparticles + SDF-I $\alpha$, (d) SDF-I $\alpha$, indicating they were more vascularized. The yellow arrows point to blood vessels. Vascular endothelial cells can be labeled by the CD3I antibody, and turn red.

Abbreviations: SDF-I $\alpha$-PPADT, SDF-I $\alpha$-loaded PPADT; $d$, day; PPADT, poly-(I,4-phenyleneacetone dimethylene thioketal); SDF-I $\alpha$, stromal cell-derived factor-I $\alpha$; NP, nanoparticle.

and participate in inflammation and repair. Studies have shown that ROS levels in wound tissues are significantly higher than normal tissues. ${ }^{25}$ Here, we also observed that during wound healing, ROS was maintained at a high level for a long time.

In the previous study ${ }^{16}$ a polymerization reaction was used to synthesize the biocompatible and responsive polymer PPADT. Then nanoparticles based on PPADT were prepared that could release encapsulated drugs in ROS-rich area of gastrointestinal tract, while kept stable in other areas of gastrointestinal tract. This property was used to create nanoparticles capable of targeting wounds. In this study, the polymer PPADT was synthesized, which degrades in response to specific signals. Encapsulated SDF- $1 \alpha$ in this polymer improved its stability in vivo, so it remained in circulation for a long time, and the responsiveness of the polymer to ROS enabled the targeted release of SDF- $1 \alpha$ in wounds and surrounding tissues.

Typically, proteins that trapped in the oil-water interface partially lose their activity during the preparation of protein-containing nanoparticles. ${ }^{26,27}$ In the present study, to minimize activity loss of the encapsulated SDF- $1 \alpha$, the temperature of the reaction system was delicately controlled, and a surfactant (sodium cholate) was added to reduce 


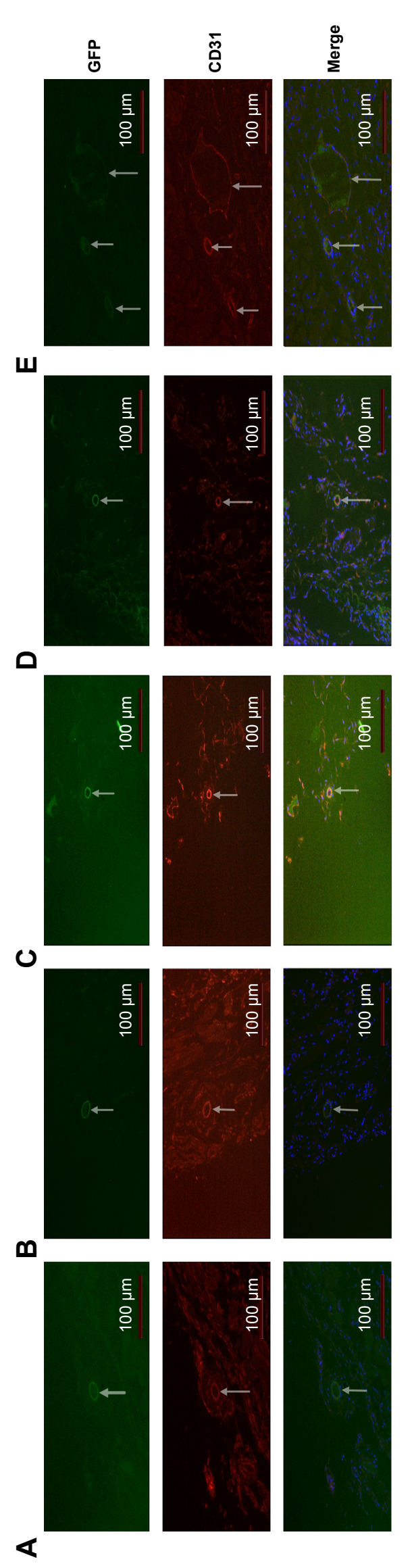

thermal denaturation of SDF- $1 \alpha$ and to keep it out of contact with the oil-water interface. As a result, the activity of encapsulated SDF- $1 \alpha$ in inducing chemotaxis of BMSCs was largely preserved as tested by the transwell migration assay. In addition, no significant effect on cell proliferation, liver and kidney function of mice, and the tissue structure of major organs were found after the treatment of these nanoparticles, suggesting a good biocompatibility with no toxicity in vitro and in vivo.

Intravenously injected nanoparticles are often captured by reticuloendothelial system-rich organs, such as the liver and spleen, and are thus rapidly cleared from the body. ${ }^{28}$ It has been demonstrated that nanoparticles $>300 \mathrm{~nm}$ or $<50 \mathrm{~nm}$ in diameter tended to aggregate in the liver, ${ }^{28}$ but nanoparticles $\sim 100 \mathrm{~nm}$ in diameter could effectively avoid phagocytosis by reticuloendothelial system and remain in the circulation for a longer time. ${ }^{29-31}$ Accordingly, the 110-nm SDF-1 $\alpha$-PPADT nanoparticles were anticipated to exist for a longer time in blood, which could facilitate the sustained transport of SDF-1 to wounded sites. Compared with the rapid drop of its blood level after intravenous injection of pure SDF- $1 \alpha$, the blood content of SDF- $1 \alpha$ in the nanoparticles group could exist at a high level within 24 hours, in well accordance with its suitable size range.

In addition to the prolonged circulation, SDF-1 $\alpha$-PPADT nanoparticles are also required to be relatively stable under normal physiological conditions, whereas sensitive to the high levels of ROS in wounded areas. To validate this functionality of nanoparticles, the in vitro release of SDF- $1 \alpha$ was studied in PBS and the ROS-rich Fenton's reagent. In both solutions, $\sim 20 \% \mathrm{SDF}-1 \alpha$ was released within 1 hour, showing a burst release effect, which might be caused by a small amount of SDF-1 $\alpha$ absorbed onto the surface of the nanoparticles during preparation and the diffusion of some SDF- $1 \alpha$ into the solutions through the pores of the nanoparticles. ${ }^{32}$ Afterward, nanoparticles in PBS released only small amount of SDF-1 $\alpha$, but those in the Fenton's reagent continued to release large amount of the encapsulated SDF-1 $\alpha$. Such results were probably attributed to the rapid cleavage of thiolketal bonds in PPADT by ROS, thus leading to the degradation of nanoparticles. The sensitivity toward ROS-endowed SDF- $1 \alpha$-PPADT nanoparticles with the capability of protecting SDF- $1 \alpha$ from enzymes in circulating blood prior to effectively releasing it in the sites of injury.

For further confirmation, the in vivo release of drugs from nanoparticles was also investigated following an intravenous 
injection of nanoparticles of various concentrations into mice with full-thickness skin defects. To exclude any biological effects caused by the burst release of SDF-1 $\alpha$, SDF-1 $\alpha$ was removed from the surfaces of the nanoparticles by dialysis. In unwounded mice, the concentration of SDF-1 $\alpha$ in the serum remained as low as $400 \mathrm{pg} / \mathrm{mL}$, providing direct evidence of the stable structure of nanoparticles in normal physiological conditions. However, because there still exist low levels of ROS, limited amounts of serum SDF-1 $\alpha$ could be detected due to its leakage from nanoparticles and the slow degradation of polymers. In mice with full-thickness skin defects, the concentration of SDF- $1 \alpha$ in the serum increased significantly to $4-8 \mathrm{ng} / \mathrm{mL}$ at $2-48$ hours after nanoparticle injection. The increase of SDF-1 $\alpha$ in the blood was probably caused by a continued degradation of nanoparticles in the wounds and surrounding tissues due to increased levels of ROS in these areas. A gradient of SDF- $1 \alpha$ between wound and blood was formed after parts of those released SDF-1 $\alpha$ entered the whole circulatory system. This suggested that PPADT nanoparticles could target the encapsulated drugs to lesions with high concentrations of ROS. Such targeting capability was further demonstrated by the strongest fluorescence in the wounds, high fluorescent signal in the surrounding tissues, and negligible fluorescence in the other sites at 12 hours post a single intravenous injection of nanoparticles containing Cy5-SDF-1 $\alpha$.

As mentioned earlier, a local SDF- $1 \alpha$ gradient could induce the homing of BMSCs, their differentiation into EPCs and vascular endothelial cells, and the subsequent vascularization. ${ }^{33,34}$ It was here observed that intravenously injected SDF-1 $\alpha$-PPADT nanoparticles accelerated the healing of full-thickness skin wounds on mice. To determine whether this was caused by enhanced homing of BMSCs, exogenous BMSCs labeled with GFP were introduced into these mice. These GFP-BMSCs not only provided a source of stem cells that could have therapeutic effects but also served as a marker for us to observe the migration of BMSCs. Consequently, the administration of SDF-1 $\alpha$-PPADT nanoparticles caused more GFP-BMSCs to localize to the wounds, leading to increased wound vascularization and accelerated wound healing.

In summary, nanoparticles fabricated by PPADT polymers were used to encapsulate a macromolecular drug, the chemokine SDF-1 $\alpha$. They could respond to ROS and deliver drugs to lesions and tissues containing large amounts of ROS, thus promoting the homing of BMSCs to the wounds, inducing wound vascularization, and enhancing wound healing. These ROS-responsive nanoparticles can be probably used in targeted biological therapies for a variety of diseases with elevated ROS, such as ischemic diseases and inflammatory diseases.

\section{Acknowledgments}

This work was financially supported by the key project of the National Natural Science Foundation of China (No 81120108015), the National Natural Science Foundation of China (Nos 81171806, 81302714), the National “973” key project of People's Republic of China (No 2012CB518100), the scientific research innovation key project of Shanghai municipal commission of education (No 2012Z90030011), Nano-tech Foundation of Shanghai Science and Technology Committee (11nm0504400) and the 1255 Foundation of Changhai Hospital (No CH125510200). The funders had no role in study design, data collection and analysis, decision to publish, or preparation of the paper.

\section{Disclosure}

The authors report no conflicts of interest in this work.

\section{References}

1. Balaji S, Keswani SG, Crombleholme TM. The role of mesenchymal stem cells in the regenerative wound healing phenotype. Adv Wound Care (New Rochelle). 2012;1(4):159-165.

2. Singer NG, Caplan AI. Mesenchymal stem cells: mechanisms of inflammation. Annu Rev Pathol. 2011;6:457-478.

3. Xi J, Yan X, Zhou J, Yue W, Pei X. Mesenchymal stem cells in tissue repairing and regeneration: progress and future. Burn Trauma. 2013; $1(1): 13-20$.

4. Kim S, Chaudhry A, Lee I, Frank JA. Effects of long-term hypoxia and pro-survival cocktail in bone marrow-derived stromal cell survival. Stem Cells Dev. 2014;23(5):530-540.

5. Thieme S, Ryser M, Gentsch M, et al. Stromal cell-derived factor-1alphadirected chemoattraction of transiently CXCR4-overexpressing bone marrow stromal cells into functionalized three-dimensional biomimetic scaffolds. Tissue Eng Part C Methods. 2009;15(4):687-696.

6. Corcione A, Ottonello L, Tortolina G, et al. Stromal cell-derived factor-1 as a chemoattractant for follicular center lymphoma B cells. $J$ Natl Cancer Inst. 2000;92(8):628-635.

7. Togel F, Isaac J, Hu Z, Weiss K, Westenfelder C. Renal SDF-1 signals mobilization and homing of CXCR4-positive cells to the kidney after ischemic injury. Kidney Int. 2005;67(5):1772-1784.

8. Lee BC, Hsu HC, Tseng WY, et al. Cell therapy generates a favourable chemokine gradient for stem cell recruitment into the infarcted heart in rabbits. Eur J Heart Fail. 2009;11(3):238-245.

9. Shen H, Cheng T, Olszak I, et al. CXCR-4 desensitization is associated with tissue localization of hemopoietic progenitor cells. J Immunol. 2001;166(8):5027-5033.

10. Hattori K, Heissig B, Tashiro K, et al. Plasma elevation of stromal cellderived factor-1 induces mobilization of mature and immature hematopoietic progenitor and stem cells. Blood. 2001;97(11):3354-3360.

11. Kommareddy S, Amiji M. Biodistribution and pharmacokinetic analysis of long-circulating thiolated gelatin nanoparticles following systemic administration in breast cancer-bearing mice. J Pharm Sci. 2007;96(2): 397-407.

12. Delie F, Blanco-Prieto MJ. Polymeric particulates to improve oral bioavailability of peptide drugs. Molecules. 2005;10(1):65-80. 
13. Okuda T, Kawakami S, Akimoto N, Niidome T, Yamashita F, Hashida M. PEGylated lysine dendrimers for tumor-selective targeting after intravenous injection in tumor-bearing mice. J Control Release. 2006;116(3):330-336.

14. Bryan N, Ahswin H, Smart N, Bayon Y, Wohlert S, Hunt JA. Reactive oxygen species (ROS) - a family of fate deciding molecules pivotal in constructive inflammation and wound healing. Eur Cell Mater. 2012;24:249-265.

15. Napoli A, Valentini M, Tirelli N, Muller M, Hubbell JA. Oxidationresponsive polymeric vesicles. Nat Mater. 2004;3(3):183-189.

16. Wilson DS, Dalmasso G, Wang L, Sitaraman SV, Merlin D, Murthy N. Orally delivered thioketal nanoparticles loaded with TNF-alpha-siRNA target inflammation and inhibit gene expression in the intestines. Nat Mater. 2010;9(11):923-928.

17. Samy RP, Thwin MM, Chow VT, Bow H, Gopalakrishnakone P. Evaluation of antibacterial activity of proteins and peptides using a specific animal model for wound healing. Methods Mol Biol. 2011;716:245-265.

18. Gasper MM, Blanco D, Cruz ME, Alonso MJ. Formulation of L-asparaginase-loaded poly(lactide-co-glycolide) nanoparticles: influence of polymer properties on enzyme loading, activity and in vitro release. J Control Release. 1998;52(1-2):53-62.

19. Murata N, Takashima Y, Toyoshima K, Yamamoto M, Okada H Anti-tumor effects of anti-VEGF siRNA encapsulated with PLGA microspheres in mice. J Control Release. 2008;126(3):246-254.

20. Hiasa K, Ishibashi M, Ohtani K, et al. Gene transfer of stromal cell-derived factor-1alpha enhances ischemic vasculogenesis and angiogenesis via vascular endothelial growth factor/endothelial nitric oxide synthase-related pathway: next-generation chemokine therapy for therapeutic neovascularization. Circulation. 2004;109(20): 2454-2461.

21. Tan Y, Shao H, Eton D, et al. Stromal cell-derived factor-1 enhances pro-angiogenic effect of granulocyte-colony stimulating factor. Cardiovasc Res. 2007;73(4):823-832.

22. Heathcote EJ, Shiffman ML, Cooksley WG, et al. Peginterferon alfa-2a in patients with chronic hepatitis $\mathrm{C}$ and cirrhosis. $N$ Engl J Med. 2000;343(23):1673-1680.
23. Misra P, Lebeche D, Ly H, et al. Quantitation of CXCR4 expression in myocardial infarction using 99mTc-labeled SDF-1alpha. J Nucl Med. 2008;49(6):963-969.

24. Ye M, Kim S, Park K. Issues in long-term protein delivery using biodegradable microparticles. J Control Release. 2010;146(2):241-260.

25. Rasik AM, Shukla A. Antioxidant status in delayed healing type of wounds. Int J Exp Pathol. 2000;81(4):257-263.

26. Jin T, Zhu J, Wu F, Yuan W, Geng LL, Zhu H. Preparing polymerbased sustained-release systems without exposing proteins to water-oil or water-air interfaces and cross-linking reagents. J Control Release. 2008;128(1):50-59.

27. Yuan W, Geng Y, Wu F, et al. Preparation of polysaccharide glassy microparticles with stabilization of proteins. Int J Pharm. 2009; 366(1-2):154-159.

28. Liu D, Mori A, Huang L. Role of liposome size and RES blockade in controlling biodistribution and tumor uptake of GM1-containing liposomes. Biochim Biophys Acta. 1992;1104(1):95-101.

29. Sonavane G, Tomoda K, Makino K. Biodistribution of colloidal gold nanoparticles after intravenous administration: effect of particle size. Colloids Surf B Biointerfaces. 2008;66(2):274-280.

30. Gaur U, Sahoo SK, De TK, Ghosh PC, Maitra A, Ghosh PK. Biodistribution of fluoresceinated dextran using novel nanoparticles evading reticuloendothelial system. Int J Pharm. 2000;202(1-2):1-10.

31. Banerjee T, Mitra S, Kumar Singh A, Kumar Sharma R, Maitra A. Preparation, characterization and biodistribution of ultrafine chitosan nanoparticles. Int J Pharm. 2002;243(1-2):93-105.

32. Ruan G, Feng SS, Li QT. Effects of material hydrophobicity on physical properties of polymeric microspheres formed by double emulsion process. J Control Release. 2002;84(3):151-160.

33. Ribeiro J, Pereira T, Amorim I, et al. Cell therapy with human MSCs isolated from the umbilical cord Wharton jelly associated to a PVA membrane in the treatment of chronic skin wounds. Int J Med Sci. 2014; 11(10):979-987.

34. Garg RK, Rennert RC, Duscher D, et al. Capillary force seeding of hydrogels for adipose-derived stem cell delivery in wounds. Stem Cells Transl Med. 2014;3(9):1079-1089. 


\section{Supplementary materials} Synthesis of poly-(I,4-phenyleneacetone dimethylene thioketal)

Poly-(1,4-phenyleneacetone dimethylene thioketal) (PPADT) was synthesized as previously described. ${ }^{16}$ Briefly, 1,4-dimethyl-thiol and 2,2-dimethoxy propane were dissolved in benzene at a molar ratio of $1: 1$ and heated to $95^{\circ} \mathrm{C}$. A catalytic amount of benzoic acid was added and the mixture was incubated at $95^{\circ} \mathrm{C}$ for 1 hour. An equal molar to 1,4-dimethyl-thiol and 2,2-dimethoxy propane of 2,2dimethoxypropane was continuously added into the mixture with a micro-pump and the reaction system was kept at $95^{\circ} \mathrm{C}$ for 12 hours. The mixture was stirred for another 12 hours, and cold hexane was then added $(50 \mathrm{~mL})$ to precipitate the final product PPADT. The molecular weight $(\mathrm{Mw})$ of the polymer was determined by gel permeation chromatography (GPC) (Agilent/Wyatt 1260, Agilent Technologies, Santa Clara, CA, USA). The chemical structure was characterized by ${ }^{1} \mathrm{H}$ NMR and ${ }^{13} \mathrm{C}$ NMR (Avance II600; Bruker Biospin, Billerica, MA, USA). ${ }^{1} \mathrm{H}$ NMR results were as follows: per repeating unit, $\left(600 \mathrm{MHz}, \mathrm{CDCl}_{3}\right) \delta$ ppm $7.30(4 \mathrm{H}), 3.87$ $(4 \mathrm{H})$, and $1.62(6 \mathrm{H})$ (Figure $\mathrm{S} 1) .{ }^{13} \mathrm{C}$ NMR results were as follows: $\left(600 \mathrm{MHz}, \mathrm{CDCl}_{3}\right) \delta$ ppm 129.304, 77.231, 77.019, $76.807,34.806$, and 30.787 (Figure S2). The molecular structure was consistent with that reported in the literature. GPC showed that the average $\mathrm{mW}$ of PPADT was $11.5 \mathrm{kDa}$ with a polydispersity index value of 1.974 .

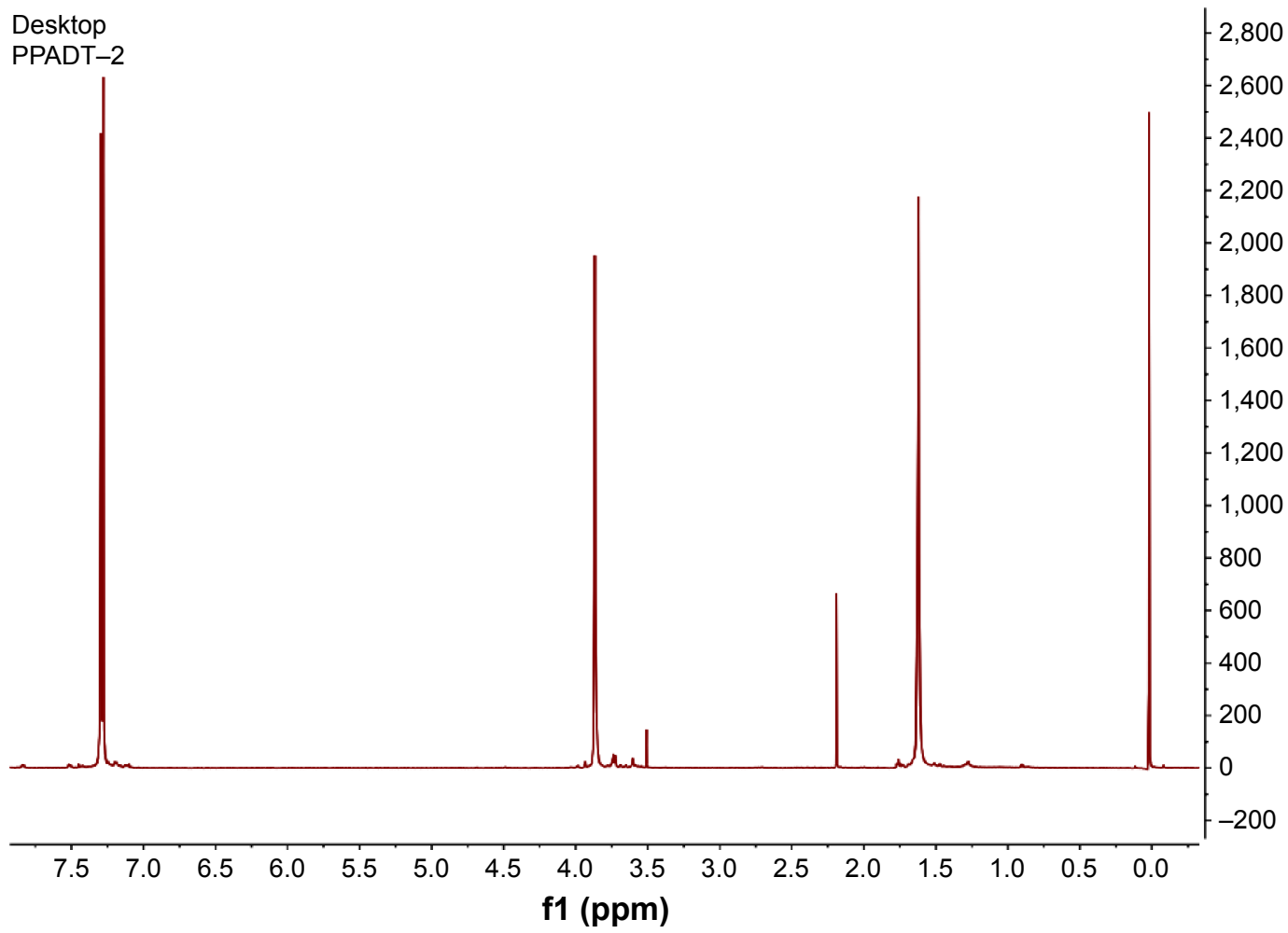

Figure SI 'H NMR of PPADT polymer.

Abbreviations: NMR, nuclear magnetic resonance; PPADT, poly-(I,4-phenyleneacetone dimethylene thioketal); ppm, part per million. 
${ }^{13} \mathrm{C}$ PPADT-2

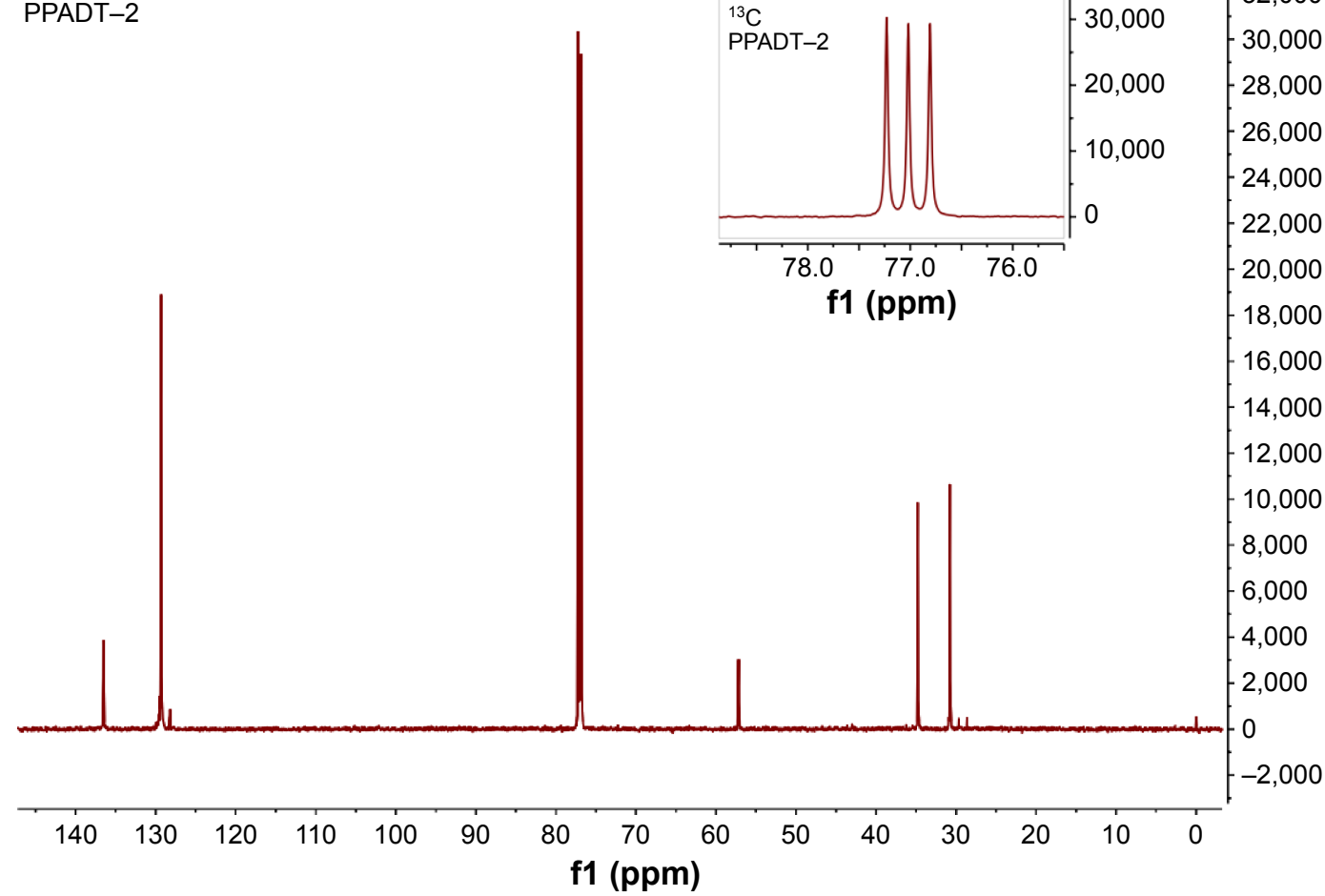

Figure S2 ${ }^{13} \mathrm{C}$ NMR of PPADT polymer.

Abbreviations: NMR, nuclear magnetic resonance; PPADT, poly-(I,4-phenyleneacetone dimethylene thioketal); ppm, part per million.

International Journal of Nanomedicine

\section{Publish your work in this journal}

The International Journal of Nanomedicine is an international, peerreviewed journal focusing on the application of nanotechnology in diagnostics, therapeutics, and drug delivery systems throughou the biomedical field. This journal is indexed on PubMed Central, MedLine, CAS, SciSearch $®$, Current Contents $\AA /$ Clinical Medicine,
Journal Citation Reports/Science Edition, EMBase, Scopus and the Elsevier Bibliographic databases. The manuscript management system is completely online and includes a very quick and fair peer-review system, which is all easy to use. Visit http://www.dovepress.com/ testimonials.php to read real quotes from published authors.

\footnotetext{
Submit your manuscript here: http://www.dovepress.com/international-journal-of-nanomedicine-journal
} 